\title{
Monitoring System Using GPS for Logistic's Key Performance Indicator
}

\author{
Abba Suganda Girsang*, Triadi Prabowo \\ Computer Science Department, BINUS Graduate Program-Master of Computer Science, Bina Nusantara University, 11480 Jakarta, \\ Indonesia
}

\author{
A R T I C L E I N F O \\ Article history: \\ Received: 24 July, 2019 \\ Accepted: 22 October, 2019 \\ Online: 22 November, 2019
}

\begin{tabular}{l}
\hline Keywords: \\
Kpi \\
Logistic \\
Gps \\
Tracking \\
Transporter \\
\end{tabular}

\begin{abstract}
A B S T R A C T
Transportation vendors are important for distribution companies to deliver goods or products. Operational problems of logistic process in transportation vendors' activities are difficult to track and monitor directly in the field, such as driver's position, the delivery, and so forth. These problems result in the difficulty to measure the performance of vendors' activities. The aim of this research is to develop a system which covers monitoring and tracking of their logistic process operation problems. The system is built based on Android integrated with GPS and GSM. This system is also equipped with the ability to recapitulate the performance of transportation vendors in running activities of logistic operation. The performance is measured from some important components in logistic process. They are task asssment, on-time delivery, completed administration and availabilty. The result of this system is capable to show the vendor transportation's key performance indicator (KPI) and minimalize bureaucratic problems.
\end{abstract}

\section{Introduction}

The rapid growth of information technology has brought many changes to various business aspects, including logistics. Modern technologies such as GPS (Global Positioning System) and RFID (Radio Frequency Identification) can be used to change semimanual process to systematic process [1]-[3]. Implementation of these technologies in logistic business sector enhances the performance of logistic process operation [4]. A survey shows that logistic company needs transparency in logistic process operation and more security [5]. GPS (Global Positioning System) is currently the most promising technology for acquiring position information in a field [6]-[9].

Manufacturers that process raw materials into ready-to-use product need logistic to transport their goods to other factories or their suppliers. Then, logistic operations provide transportation service of goods to desired locations (customer included) or warehousing. There are companies which keep their logistic function is part of the companies operation/business process and others keep their logistic function by using vendor transporters (outsourcing logistic) [10]-[12]. Both of them have advantages and disadvantages. Outsourcing logistic function has a high risk of loss competencies which may lead to high cost [13], 14] and hard to monitor their operation and management. Many researches look

*Abba Suganda Girsang, Email: gandagirsang@yahoo.com into logistic function outsource issues but few addressed so far about in-house logistic provider issues [10], [15], [16].

KPI (key performance indicator) in logistic business sector is mainly used to measure and show gaps between fundamental logistic process while delivering goods and the expected performance proposed by the company [17], [18]. Real-time data play a crucial part in this case, because obtaining information and giving feedback to correspondents can be done more quickly (between operators and courier). Implementation of websocket may help achieve that, because its behavior provides full-duplex, communication channel that operates through a single connection which builds scalable and real-time application [19] .

We found empirical findings based on some cases in company. However, in this paper, a cement company, PT. XYZ, is used as a reference. This company uses outsourcing logistic function (vendor transporter). It is facing some issues, such as the incapability of the to complete given assignments, goods not delivered on time, incomplete documents, and availability of fleet difficult to maintain and ready to use. This study proposes a new approach to implementing fleet-management and vendor performance evaluation (KPI). Monitoring application based on node.js platform and android as its client is implemented in this case. It is expected to minimize the risk of outsourcing its logistic provider such as monitoring transporter movement and recording the whole trip data, which is later used to evaluate the transporter's 
performance in doing logistic functions, and capable to evaluate vendor transporter KPI.

The study provides a system of performance for companies which use logistic transporters based on tour records of their drivers. This system is built based on four indicators obtained from the activities of the drivers.

\section{Proposed Method}

The proposed method is mainly aimed to identify the criteria which should be considered in vendor transporter work performance (KPI) evaluation aspect. We include relevant KPI aspects such as task assignment, manageable delivery time, completed administration and fleet availability management and its system design to achieve related aspects.

\subsection{System design}

Many technique designs are proposed to develop the system. Figure 1 indicates the scheme of our framework to implement monitoring logistic operation system, which is integrated with GPS (global positioning system) to monitor fleet movement in an ongoing delivery process. By using device (smartphone) on each transporter, a real-time communication between transporter and head officer (HO) can be done. It look like using emitting data transaction through websocket [20]. It is to achieve full-duplex communication between client and server.

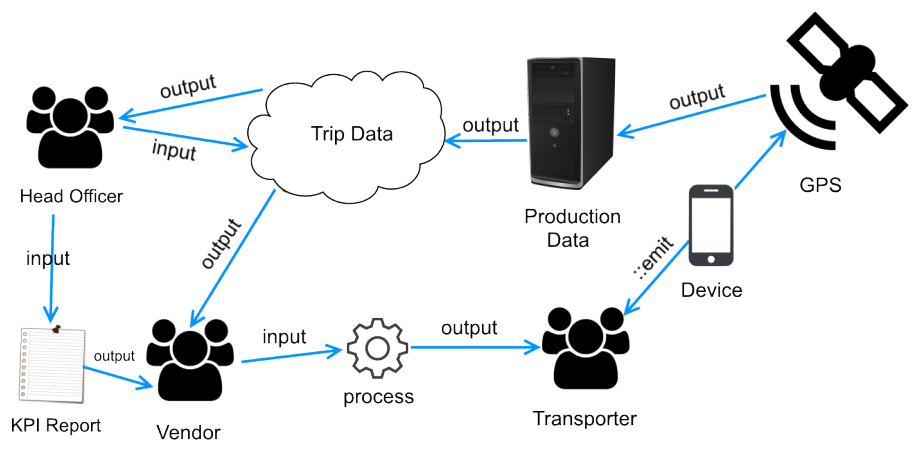

Figure 1: Proposed framework scheme

Three main actors in logistic function operation, which are $\mathrm{HO}$ (head officer), vendor transporter, and transporter (driver), are involved in the evaluation of vendor transporter KPI. Internal staff as head officer handles all data transactions between headquarter (HQ) and client (in this case vendor transporter and driver). The design steps can be described as follows. First, head officer input the required trip data (task assignment) which will be assigned to selected vendor. Then, it is processed by vendor and given to transporter (driver). All activities recorded in application device is bundled into one production data including the history of transporter position using GPS emitted from the device. It becomes an output to trip data history. Then, the trip data will be processed by head officer to assess or evaluate KPI of vendor transporter within each evaluation period time.

There are some steps to develop real-time monitoring and tracking system.

Business Requirement Analysis. This phase gathers information regarding business process from process business by interview with related job description required to obtain the requirements.
User Requirement Analysis. This phase is to obtain information from process owner regarding the new proposed model.

Evaluation analysis. Based on requirements analysis, the best method is chosen and transformed into suitable aspects evaluation.

Prototyping. This step is conducted in the architectural design and development of products or services. In this case, the requirements are transformed into an application to understand the system method or concepts.

Implementation. In this phase, the new proposed method is implemented which is customized based on existing business model and solving the current problem.

Reporting (Documentation). Reporting or documentation is taken to track which parts of model is proven to be successful or failed as the solution of the problems.

\subsection{The Interview}

One of the techniques to obtain information and data in this research is using interview [21]. The discussion of process logistic and performance is done with all stakeholders related to the KPI. Some questions used are listed below.

1. What is the SOP (standard operational procedure) of logistic function in your company?

2. What issues are faced by your company with the current SOP?

3. How can the master data be obtained?

4. What is going to happen if customers reject the delivery?

5. What is going to happen if fleets or vehicles get trouble on delivery?

6. Can vendor reject delivery orders?

7. Can transporter vendor track their driver on their own or only based on your company's monitoring function?

8. What is the expectation of this proposed system?

9. What is the KPI aspect you want to evaluate?

Table 1: KPI aspect evaluation

\begin{tabular}{|l|l|c|}
\hline Aspects & Description & Grade \\
\hline Task assignment (TA) & $\begin{array}{l}\text { Vendor capable to } \\
\text { complete given DO }\end{array}$ & $25 \%$ \\
\hline $\begin{array}{l}\text { On-Time Delivery } \\
\text { (OTD) }\end{array}$ & $\begin{array}{l}\text { Vendor capable to } \\
\text { deliver goods on-time }\end{array}$ & $25 \%$ \\
\hline $\begin{array}{l}\text { Completed } \\
\text { Administration (CA) }\end{array}$ & $\begin{array}{l}\text { Vendor capable to } \\
\text { submit required } \\
\text { document }\end{array}$ & $25 \%$ \\
\hline Availability (A) & $\begin{array}{l}\text { Vendor capable to make } \\
\text { fleet ready in use } \\
\text { (delivery order given) }\end{array}$ & $25 \%$ \\
\hline Total & \multicolumn{2}{|l}{$100 \%$} \\
\hline
\end{tabular}

\subsection{KPI Evaluation}

The proposed system is developed based on vendor transporter's KPI assessment. This KPI evaluation is important for PT. XYZ to make decisions whether to continue outsourcing the 
logistic with selected vendor or terminate the vendor and replace with a new one. The discussions and interviews were conducted by the authors with relevant parties to formulate KPI. As the results, there are four aspects as shown in Table 1. These aspects are formulated to evaluate KPI based on user requirements and the issues of outsourcing logistic functions. The four aspects have the same percentage because they are considered as having the same importance.

The four aspects on Table 1 are built based on the variables as shown in Eq (1), Eq. (2), Eq. (3) and Eq.(4).

Task Assignment (TA). Variable TA is derived from assignment (delivery order) completed by vendor divided by total assignment given per evaluation period as shown Eq. (1).

$$
T A=\frac{\begin{array}{l}
\text { Completed assignment } \\
\text { (per evaluation period })
\end{array}}{\text { Total assignment }(\text { per evaluation period })} \times 100
$$

On-Time Delivery Target (OTD). Variable OTD is derived from completed delivery expectation (by customer) divided by total assignment given per evaluation period as shown Eq. (2).

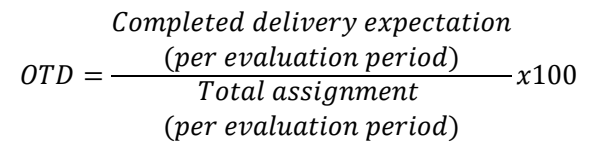

Completed Administration (CA). Variable CA is derived from vendor capability to submit required document or return document to PT. XYZ as shown Eq. (3).

$$
C A=\frac{\begin{array}{c}
\text { Returned administration } \\
(\text { per evaluation period })
\end{array}}{\text { Total assignment }(\text { per evaluation period })} \times 100
$$

Availability (A). Variable A is derived from total accepted assignment or delivery order given by internal staff of PT. XYZ, and vendor must provide fleet based on contract while outsourcing permission as shown Eq. (4).

$$
A=\frac{\begin{array}{c}
\text { Total accepted assignment } \\
(\text { per evaluation period })
\end{array}}{\begin{array}{c}
\text { Total contracted unit } \\
(\text { per evaluation period })
\end{array}} \times 100
$$

\section{Results and Discussion}

In the requirement analysis phase, user is able to set up fleet profile, fleet type, license number, and owner of the fleet. He / she can set up feature of transporter data registered under the vendor. Some features can be developed such as the capability to monitor and track location which allows user to use navigation to the destination place noted in delivery note document with Google Maps, delivery order allocation which allows user to set up delivery order dynamically and specifically, the function of AutoGrab which allows user to grab delivery order along the way in specific radius near loading plant point, the function of AutoRejected when the transporter gets limit to order capacity per day, and emergency feature which allows transporter and operator (head officer) to communicate through application message system real-time (using websocket).

Figure 2 shows the proposed business process in logistic operation. The process starts with creating delivery order, then HO determines maps of transporter routes. After mapping transporter routes, driver will confirm the given task to accept or reject delivery order (DO). If transporter accepts the DO, he / she gets delivery number (usually called delivery note). After the transporter has the route, then it will be sent to customer. Once customer accepts the order, then customer will sign receipt document. However, if the customer rejects, the document will be returned back to $\mathrm{HO}$.

Figure 3 shows the flow of the proposed system that can be adjusted dynamically to the defined KPI aspects. It is based on empirical findings in manufacture or company which outsources their logistic provider. There are four main data characteristics flow as: User request report, in which users will request through HTTP to get the report; in this case, the calculation is done in four aspects of KPI previously mentioned. Next is collect data, which is the data source from the delivery process or operational logistics processes that have been running. Data is stored on a local database that is directly integrated with the system and the database residing on the ERP system. The next is data processing, in which data obtained either through the ERP or local database provisioned in the development of this application is processed through back-end. This request will end to the user in the form of report. After getting the result, reports that have been processed will be displayed on the application interface to be viewed by the user who performs data request to be used as consideration or decision making from the user. Figure 4, Figure 5, Figure 6, Figure 7, and figure 8 show the KPI result report based on selected aspect and period. The proposed KPI calculates the overall KPI grade or score based on recorded activity data done in evaluation period time which include task assignment, on-time delivery target, completed administration and availability. The formula of the overall KPI is shown in Eq. (5).

$$
\mathrm{KPI}=\frac{T A+O T D+C A+A}{4}
$$

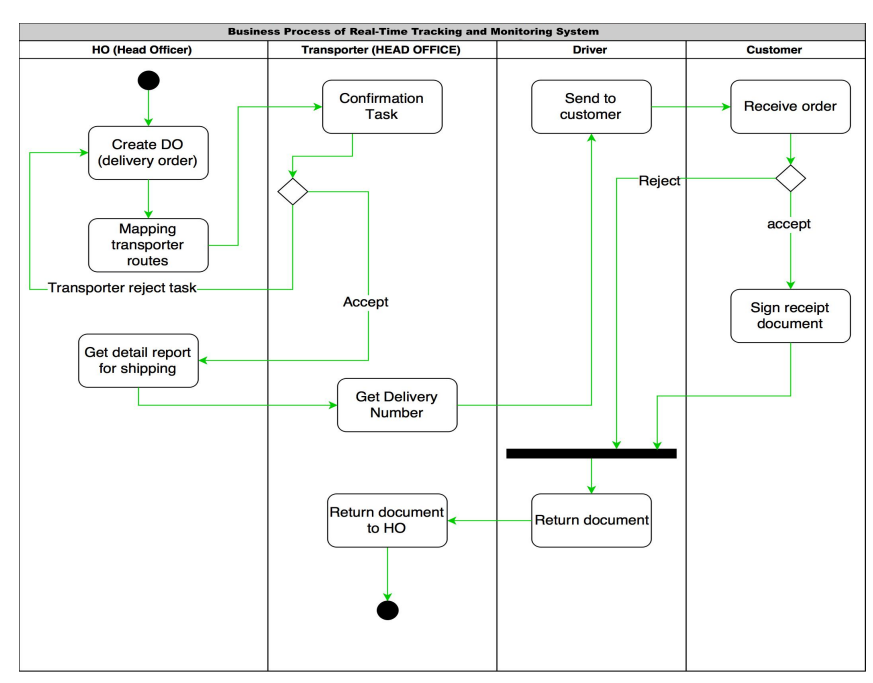

Figure 2: Proposed business process in manufacturer 


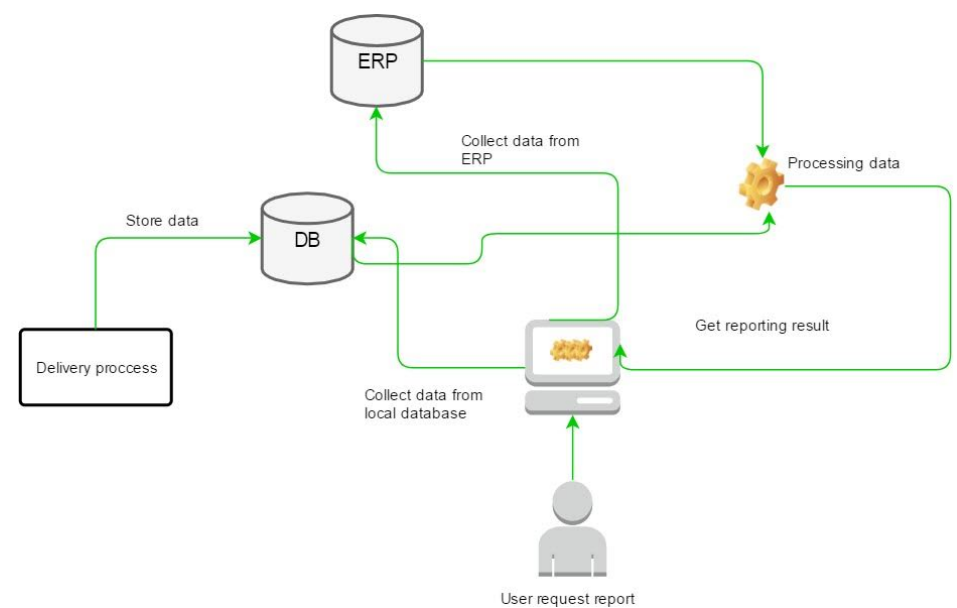

Figure 3: Flow system to evaluate KPI based on defined aspects

The Eq. (5) is calculated is based on Eq. (1), Eq.(2), Eq.(3) and Eq.(4). The result of Eq. (1) is be shown in Figure.4

\begin{tabular}{lcrcr} 
nama_vendor & total_assignment & completed_assignment & TA \\
\hline ANDALAN NUSA PR & 43 & 38 & 88.37 \\
\hline BHANDA CILEGON & 33 & 27 & 81.82 \\
\hline LINTAS JAWAMAS & 19 & 12 & 63.16 \\
\hline MAGA NIAGA & 22 & 15 & 68.18 \\
\hline SINAR PUTRA & 15 & 9 & 60.00 \\
\hline LIVINA MULYA ABADI & 7 & 6 & 85.71 \\
TRI KUSUMA JAYA PERKASA, PT & 27 & 25 & 92.59 \\
TRANSINDO TRANSPORTASI BAHARI. PT & 3 & 3 & 100.00
\end{tabular}

Figure 4 the sample data of task assignment

\begin{tabular}{lrrcc|}
\hline nama_vendor & total_assignment & on_time_delivery & OTD \\
\hline ANDALAN NUSA PR & 43 & 10 & 23.26 \\
\hline BHANDA CILEGON & 33 & 5 & 15.15 \\
\hline LINTAS JAWAMAS & 19 & 8 & 42.11 \\
\hline MAGA NIAGA & 22 & 4 & 18.18 \\
\hline SINAR PUTRA & 15 & 7 & 46.67 \\
\hline LIVINA MULYA ABADI & 7 & 0 & 0.00 \\
\hline TRI KUSUMA JAYA PERKASA, PT & 27 & 17 & 62.96 \\
\hline TRANSINDO TRANSPORTASI BAHARI.PT & 3 & 0 & 0.00 \\
\hline
\end{tabular}

Figure 5 the sample data of On-Time Delivery Target.

The result of Eq. (3) can be shown on Figure 6

\begin{tabular}{|lrrc|}
\hline nama_vendor & total_assignment & return_dn & CA \\
\hline ANDALAN NUSA PR & 43 & 26 & 60 \\
\hline BHANDA CILEGON & 33 & 18 & 55 \\
\hline LINTAS JAWAMAS & 19 & 6 & 32 \\
\hline MAGA NIAGA & 22 & 7 & 32 \\
\hline SINAR PUTRA & 15 & 3 & 20 \\
\hline LIVINA MULYA ABADI & 7 & 0 & 0 \\
\hline TRI KUSUMA JAYA PERKASA, PT & 27 & 16 & 59 \\
\hline TRANSINDO TRANSPORTASI BAHARI, PT & 3 & 1 & 33 \\
\hline
\end{tabular}

Figure 6 the sample data of completed administration
The result of Eq. (4) can be shown on Figure 7

\begin{tabular}{lrrrr}
$\begin{array}{l}\text { nama_vendor } \\
\text { ANDALAN NUSA PR }\end{array}$ & total_assignment & avail_unit & AVG_unit_per_day & A \\
\hline BHANDA CILEGON & 43 & 50 & 1 & 98.00 \\
\hline LINTAS JAWAMAS & 33 & 20 & 1 & 95.00 \\
\hline MAGA NIAGA & 19 & 10 & 1 & 90.00 \\
\hline SINAR PUTRA & 22 & 10 & 1 & 90.00 \\
\hline LIVINA MULYA ABADI & 15 & 10 & 1 & 90.00 \\
\hline TRI KUSUMA JAYA PERKASA, PT & 7 & 5 & 0 & 100.00 \\
\hline TRANSINDO TRANSPORTASI BAHARI, PT & 27 & 20 & 1 & 95.00 \\
\hline
\end{tabular}

Figure 7 the sample data of availability.

Superuser $>$ Vendor KPI

KPIAspect

Task Assignment $\quad$ May

\begin{tabular}{lllcccc}
\hline Vendor ID & Nama Vendor & Completed Assignment & Total Assignment(Period) & Grade & Action \\
\hline LG727317 & ANDALAN NUSA PR & 10 & 10 & 100 & Detail \\
\hline LG472742 & MITRA TRANSPORTASI PR & 15 & 20 & 75 & Detail \\
\hline LG123123 & JAYAPR & 12 & 15 & 80 & Detail \\
\hline LG554575 & KARINDO MITRA BERSAUDARA PR & 10 & 10 & 100 & Detail \\
\hline & & & 17 & & Detail \\
\hline LG887422 & HARMONI JAYA PR & 8 & 17 & \\
\hline
\end{tabular}

Figure.8: KPI result report

\begin{tabular}{|c|c|c|c|c|c|c|c|c|}
\hline Device ID & UUID & Timestamp & Created at & Lat & Lng & Accuracy & Activity & Battery \\
\hline $125 c 663531137755$ & $67 \mathrm{bd} 3 \mathrm{ad} 48 \mathrm{e} 70$ & 09/14, 14:20:35:1 & $09 / 14,14: 20: 42: 0$ & 45.519408 & .73 .6168163 & 13 & still (100\%) & - \\
\hline $125 c 6635311 ; 7755$ & d7801330e1e6 & 09/14, 14:18:37:3 & $09 / 14,14: 20: 41: 8$ & 45.5192516 & .73 .6168692 & 15 & on foot (62\%) & $96 \%$ \\
\hline $125 c 663531137755$ & 07ad5111b499 & 09/14, 14:18:06:4 & 09/14, 14:20:41:8 & 45.5195434 & .73 .6163816 & 10 & on_foot (100\%) & 968 \\
\hline $125 c 663531137 f 55$ & e725aa24facc & 09/14, 14:17:36:4 & 09/14, 14:20:41:8 & 45.5199382 & .73 .6159686 & 8 & on_foot (100\%) & 968 \\
\hline $125 c 663531\{37 f 55$ & c93c526ebd10 & 09/14, 14:17:01:4 & $09 / 14,14: 20: 41: 8$ & 45.5203738 & .73 .6156441 & 6 & on_foot (85\%) & $96 \%$ \\
\hline $125 c 663531\{37 f 55$ & $8 c 9 d f c 3943 e 5$ & $09 / 14,14: 15: 26: 1$ & $09 / 14,14: 20: 41: 8$ & 45.5203253 & .73 .6149459 & 4 & on_foot (85\%) & 968 \\
\hline $125 \mathrm{c} 663531137555$ & $c 2845 c 8 a 8 c 4 d$ & 09/14, 14:14:56:1 & $09 / 14,14: 20: 41: 8$ & 45.5201631 & .73 .6143485 & 4 & on foot (92\%) & $96 \%$ \\
\hline $125 c 663531137 f 55$ & $433 c f 408 c 55 c$ & $09 / 14,14: 14: 26: 1$ & $09 / 14,14: 20: 41: 8$ & 45.5198925 & .73 .6137712 & 5 & on foot (100\%) & $96 \%$ \\
\hline $125 c 663531137755$ & $8 b a 00060$ edf3 & 09/14, 14:13:56:1 & $09 / 14,14: 20: 41: 8$ & 45.5195956 & .73 .6131462 & 5 & on foot (92\%) & $96 \%$ \\
\hline $125 \mathrm{c} 663531137555$ & $000 \mathrm{~b} 7 \mathrm{ea0} \mathrm{eb} 48$ & 09/14, 14:13:21:4 & 09/14, 14:20:41:8 & 45.5193214 & .73 .6125308 & 4 & on foot (100\%) & $96 \%$ \\
\hline $125 c 663531137555$ & bf $32 \mathrm{cec} 0875 f$ & $09 / 14,14: 12: 51: 4$ & 09/14, 14:20:41:8 & 45.5190425 & .73 .6119658 & 4 & on_foot (85\%) & $96 \%$ \\
\hline $125 \mathrm{c} 663531137155$ & 8925a0ae53fo & 09/14, 14:12:26:1 & $09 / 14,14: 20: 41: 8$ & 45.5188121 & .73 .6113978 & 4 & onffoot (100\%) & $96 \%$ \\
\hline $125 \mathrm{c} 663531137755$ & $4 c 4822 d 1 a 3 b a$ & 09/14, 14:11:41:0 & $09 / 14,14: 20: 41: 8$ & 45.5184887 & .73 .6105816 & 6 & on_foot (69\%) & $96 \%$ \\
\hline $125 c 663531137755$ & b2035adf5139 & 09/14, 14:11:16:0 & 09/14, 14:20:41:7 & 45.5182135 & .73 .6100563 & 8 & onffoot (100\%) & $96 \%$ \\
\hline $125 c 663531137755$ & a08cba638951 & $09 / 14,14: 10: 46: 0$ & 09/14, 14:20:41:8 & 45.5179428 & .73 .6095 & 4 & on_foot (85\%) & 978 \\
\hline $125 \mathrm{c} 663531137755$ & $660 \mathrm{~d} 4 \mathrm{e} 04 \mathrm{e} 4 \mathrm{e}$ & $09 / 14,14: 10: 16: 0$ & 09/14, 14:20:41:7 & 45.517664 & .73 .6088969 & 4 & onffoot (100\%) & $97 \%$ \\
\hline $125 \mathrm{c} 663531137755$ & $29 \mathrm{e} 654415 \mathrm{bd} 7$ & 09/14, 14:09:41:0 & 09/14, 14:20:44:4 & 45.5173972 & .73 .6082512 & 5 & onffoot (100\%) & 9778 \\
\hline $125 c 663531137 f 55$ & $8 a 775 a 52 c 79 e$ & 09/14, 14:09:11:0 & 09/14, 14:20:44:4 & 45.517105 & .73 .6077112 & 6 & on foot (69\%) & $97 \%$ \\
\hline $125 c 663531137 f 55$ & 9ca51cfce82f & 09/14, 14:08:31:0 & $09 / 14,14: 20: 44: 4$ & 45.516966 & .73 .6070105 & 10 & on_foot (100\%) & $97 \%$ \\
\hline $125 c 663531137755$ & $\mathrm{~d} 52 \mathrm{e} 50 \mathrm{~b} 493 \mathrm{e} 0$ & 09/14, 14:08:01:0 & 09/14, 14:20:44:3 & 45.5173395 & .73 .6066499 & 4 & on foot (100\%) & $97 \%$ \\
\hline $125 c 663531137755$ & e2392ccbd 3 fe & 09/14, 14:07:24:5 & $09 / 14,14: 20: 44: 4$ & 45.5177335 & .73 .6061499 & 20 & onfoot (92\%) & 978 \\
\hline
\end{tabular}

Figure 9: Monitoring data sample

This system uses the plugin cordova background geolocation to monitor and track module for implementing the system as shown in Figure 9 [22]. It logs all the required data to monitor transporter movements, such as device id, uuid, timestamp, latitude, longitude, accuracy, and activity (on_foot or stay still). Figure 10 shows the GPS (global positioning system) or GNSS (Global navigation satellite system) which allows users to 


\section{A.S. Girsang et al. / Advances in Science, Technology and Engineering Systems Journal Vol. 4, No. 6, 32-37 (2019)}

determine location (geo positioning) from satellite signal reception [23]. As table 2 indicates, the authors performed the trial using the proposed system in transporter while doing delivery. Trial done on Oct 2019 shows fleet movement with registered trip ID and recorded date of trial This system has a unique system which makes the process efficient and transparent. This system is also very useful for company PT XYZ for monitoring the drivers' activities. It can alsorate the transportation vendor. This system is able to evaluate the KPI of transportation vendor at PT. XYZ, which is influential in decision-making for contract extension between transportation vendors and PT. XYZ.

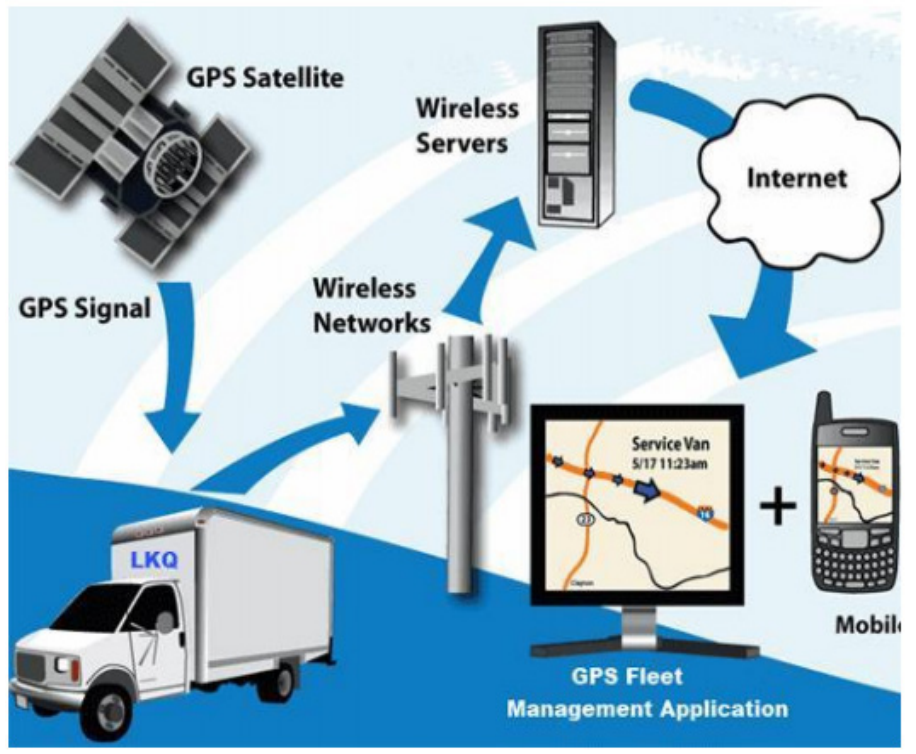

Figure 10: Monitoring process of logistic function

Table 2: Data sample result using monitoring system on transporter fleet

\begin{tabular}{|l|c|c|c|}
\hline \multicolumn{1}{|c|}{ ID } & ID Trip & LatLong & Date \\
\hline SS998710-1570547100000 & J21023 & $51.219243,4.416459$ & $10 / 9 / 201919: 44$ \\
\hline SS998710-1570547555000 & J21023 & $51.218571,4.422290$ & $10 / 9 / 201919: 49$ \\
\hline SS998710-1570547865000 & J21023 & $51.218100,4.425086$ & $10 / 9 / 201919: 55$ \\
\hline SS998710-1570548235000 & J21023 & $51.215775,4.431201$ & $10 / 9 / 201920: 01$ \\
\hline SS998710-1570548851000 & J21023 & $51.213522,4.445634$ & $10 / 9 / 201919: 44$ \\
\hline SS998710-1570633500000 & J21023 & $51.218243,4.414238$ & $10 / 10 / 201917: 05$ \\
\hline SS998710-1570633955000 & J21023 & $51.219722,4.415869$ & $10 / 10 / 201917: 12$ \\
\hline SS998710-1570634265000 & J21023 & $51.220797,4.418186$ & $10 / 10 / 201917: 17$ \\
\hline SS998710-1570634635000 & J21023 & $51.224990,4.417028$ & $10 / 10 / 201917: 23$ \\
\hline SS998710-1570634902000 & J21023 & $51.226182,4.417764$ & $10 / 10 / 201917: 28$ \\
\hline SS998710-1570635251000 & J21023 & $51.229251,4.420281$ & $10 / 10 / 201917: 34$ \\
\hline SS998710-1570636124000 & J21023 & $51.230112,4.422311$ & $10 / 10 / 201917: 48$ \\
\hline SS998710-1570636415000 & J21023 & $51.230079,4.426176$ & $10 / 10 / 201917: 53$ \\
\hline SS998710-1570636696000 & J21023 & $51.230818,4.430296$ & $10 / 10 / 201917: 58$ \\
\hline SS998710-1570826559118 & J243354 & $51.230991,4.429542$ & $10 / 11 / 201908: 24$ \\
\hline SS998710-1570826561121 & J243354 & $51.229908,4.429128$ & $10 / 11 / 201908: 32$ \\
\hline SS998710-1570826562122 & J243354 & $51.229641,4.426468$ & $10 / 11 / 201908: 37$ \\
\hline SS998710-1570826563120 & J243354 & $51.230152,4.424990$ & $10 / 11 / 201908: 45$ \\
\hline SS998710-1570826564121 & J243354 & $51.229244,4.424197$ & $10 / 11 / 201908: 50$ \\
\hline SS998710-1570826565121 & J243354 & $51.228151,4.423330$ & $10 / 11 / 201909: 02$ \\
\hline SS998710-1570826566118 & J243354 & $51.228791,4.421419$ & $10 / 11 / 201909: 07$ \\
\hline SS998710-1570826567121 & J243354 & $51.229881,4.420538$ & $10 / 11 / 201909: 12$ \\
\hline
\end{tabular}

\section{Conclusion}

This paper has presented a new approach based on empirical findings and trial in a cement manufacturer outsourcing logistic service. KPI evaluation based on real-time data monitoring is important to determine transporter performance and solution to the issues by outsourcing logistic process function.

This approach will be applied to studies of $t$ logistic business process resulting in KPI evaluation.

\section{References}

[1] K. R. Trivedi and P. M. Dhiren, "Integration of GPS and GSM for the Weather Monitoring System," Bulletin of Electrical Engineering and Informatics, vol. 1, no. 3, pp. 209-212, 2012.

[2] D. Liu, X. Cao, X. Zhou, and M. Zhang, "Cold Chain Logistics Information Monitoring Platform Based on Internet of Vehicles," in 2019 International Conference on Intelligent Transportation, Big Data \& Smart City (ICITBS), 2019, pp. 348-351.

[3] S. Fazel and J. Javad, "A Highly Efficient and Linear Class AB Power Amplifier for RFID Application," Bulletin of Electrical Engineering and Informatics, vol. 4, no. 2, pp. 147-154, 2015.

[4] M. R. Kaloop, E. Elbeltagi, J. W. Hu, and A. Elrefai, "Recent advances of structures monitoring and evaluation using GPS-time series monitoring systems: A review," ISPRS Int. J. Geo-Information, vol. 6, no. 12, p. 382, 2017.

[5] C. Kandel, M. Klumpp and T. Keusgen, "GPS based Track and Trace for Transparent and Sustainable Global Supply Chains," in 17th International Conference on Concurrent Enterprising, Aachen, Germany, 2011.

[6] K. R. Prasanna and M. Hemalatha, "RFID GPS and GSM based logistics vehicle load balancing and tracking mechanism," Procedia Engineering, vol. 30, pp. 726-729, 2012.

[7] M. Bottero, C. B. Dalla and F. P. Deflorio, "Wireless sensor networks for traffic monitoring in a logistic centre," ransportation Research Part C: Emerging Technologies, vol. 26, pp. 99-124, 2013.

[8] X. M. Guo, L. S. Chen, M. Chen and C. L. Peng, "Design of real-time ECG monitoring system based on smart-phone," Application Research of Computers, vol. 6, p. 55, 2010.

[9] Y. Yan, X. Hao and W. Wang, "Location-Based Services and Privacy Protection under Mobile Cloud Computing," Bulletin of Electrical Engineering and Informatics, vol. 4, no. 4, pp. 345-354, 2015.

[10] R. Wilding and R. Juriado, "Customer perceptions on logistics outsourcing in the European consumer goods industry," International Journal of Physical Distribution \& Logistics Management, vol. 34, no. 8, pp. 628-644, 2004.

[11] M. Kiliç, A. Günsel, and H. G. Çekmecelioğlu, "The Effects of Outsourcing in Logistics Services to Competitive Advantage," Eur. J. Multidiscip. Stud., vol. 1, no. 4, pp. 233-242, 2016.

[12] S. Zailani, M. R. Shaharudin, K. Razmi, and M. Iranmanesh, "Influential factors and performance of logistics outsourcing practices: an evidence of malaysian companies," Rev. Manag. Sci., vol. 11, no. 1, pp. 53-93, 2017.

[13] B. Quelin and F. Duhamel, "Bringing together strategic outsourcing and corporate strategy: Outsourcing motives and risks," European management journal, vol. 21, no. 5, pp. 647-661, 2003.

[14] M. Abdur Razzaque and S. C. Chang, "Outsourcing of logistics functions: a literature survey," International Journal of Physical Distribution \& Logistics Management, vol. 2, pp. 89-107, 1998.

[15] D. Pyza, R. Jachimowski, I. Jacyna-Gołda, and K. Lewczuk, "Performance of equipment and means of internal transport and efficiency of implementation of warehouse processes," Procedia Eng., vol. 187, pp. 706-711, 2017.

[16] K. Moons, G. Waeyenbergh, and L. Pintelon, "Measuring the logistics performance of internal hospital supply chains-a literature study," Omega, vol. 82 , pp. 205-217, 2019.

[17] D. Radović and Ž. Stević, "Evaluation and selection of KPI in transport using SWARA method," Int. J. Transp. Logist., vol. 18, no. 44, pp. 60-68, 2018.

[18] A. Weber and R. Thomas, "Key performance indicators," Measuring and Managing the Maintenance Function, 2005

[19] Y.-H. Zhao, "Evaluation model of third-party logistics customer service quality based on KPI," Logistics Sci-Tech, 2009.

[20] V. Pimentel and B. G. Nickerson, "Communicating and Displaying RealTime Data with WebSocket," IEEE Internet Computing, vol. 16, no. 4, pp. 45-53, 2012.

[21] R. Opdenakker, "Advantages and disadvantages of four interview techniques in qualitative research.," Forum Qualitative Sozialforschung/Forum: Qualitative Social Research, vol. 7, no. 4, 2006. 
A.S. Girsang et al. / Advances in Science, Technology and Engineering Systems Journal Vol. 4, No. 6, $32-37$ (2019)

[22] T. Software, "The most sophisticated background location-tracking \&amp," 2015. [Online]. Available: https://github.com/transistorsoft/cordovabackground-geolocation-lt.

[23] D. Abha, H. Shah, K. Shah and M. Vala, "Global Positioning System for Object Tracking," International Journal of Computer Applications, vol. 109, no. 8 , pp. $40-45,2015$. 